\title{
PENGARUH PERUBAHAN LAJU ALIRAN \\ TERHADAP TEKANAN DAN JENIS ALIRAN \\ YANG TERJADI PADA ALAT UJI PRAKTIIKUM MEKANIKA FLUIDA
}

\author{
Untung Surya Dharma, Galih Prasetyo \\ Jurusan Teknik Mesin Universitas Muhammadiyah Metro \\ Jl. Ki Hajar Dewantara No. 116 Iringmulyo Kota Metro ( 0725 ) 42445-42454 \\ Email: untungsdh@yahoo.co.id
}

\begin{abstract}
Abstrak
Telah dibuat sebuat alat praktikum Mekanika Fluida di Laboratorium Mekanika Fluida Teknik Mesin Teknik Mesin Universitas Muhammadiyah Metro. Untuk mengetahui kinerja alat uji tersebut maka dilakukan penelitian tentang pengaruh perubahan laju aliran terhadap tekanan dan jenis aliran. Pipa uji yang digunakan adalah pipa $p v c$, pipa acrylic, dan pipa baja. Fluida yang digunakan adalah air, yang digunakan untuk mensirkulasikan fluida ke dalam pipa uji adalah pompa sentrifugal. Alat uji mekanika fluida ini dibuat dalam skala laboraturium atau alat praktikum, sehingga dapat digunakan untuk kegiatan praktikum. Pengujian dilakukan untuk mendapatkan laju aliran dan perubahan tekanan dengan menggunakan flowmeter dan manometer U. Jeniss aliran juga diketahui dengan pengamatan langsung pada saat pengujian dilakukan dan dari peritungan Bilangan Reynold. Dari hasil penelitian, diketahui bahwa perubahan tekanan yang terjadi pada bagian pipa lurus $\left(\mathrm{P}_{1}\right)$, pipa pengecilan $\left(\Delta \mathrm{P}_{3}\right)$, pipa belokan $\left(\Delta \mathrm{P}_{4}\right)$, pipa beda bahan $\left(\Delta \mathrm{P}_{5}\right)$ dan pipa lurus $\left(\Delta \mathrm{P}_{6}\right)$ berbanding lurus dengan semakin bertambahnya laju aliran fluida. Sementara perubahan tekanan pada pipa pembesaran $\left(\Delta \mathrm{P}_{2}\right)$ berbanding terbalik dengan semakin bertambahnya laju aliran fluida. Bilangan Reynold yang didapat sebesar 12690,39 sehingga jenis aliran yang terjadi adalah jenis aliran turbulen. Perubahan tekanan paling besar terjadi pada satu titik bagian pipa lurus yaitu sebesar $2354 \mathrm{~N} / \mathrm{m}^{2}$.
\end{abstract}

Kata kunci : Laju aliran, tekanan, jenis aliran.

\section{PENDAHULUAN}

Setiap hari tanpa kita sadari kita selalu berhubungan dengan fluida. Kita dapat melihat instalasi perpipaan air pada rumah yang kita tempati. Fenomena pada fluida yang dapat kita lihat dalam kehidupan sehari-hari.

Pipa memiliki berbagai bentuk penampang dan ukurannya. Yang sering banyak digunakan oleh umum adalah pipa dengan penampang lingkaran dengan menggunakan material pipa yang digunakan bermacam-macam, diantaranya yaitubacrylic, $P V C$, dan logam [1]. Pemilihan material pipa disesuaikan dengan kebutuhan dan tujuannya. Didunia industri sebagian besar fluidanya mengalir pada pipa tertutup, masalah utama yang terjadi antara lain :

1) Terjadinya gesekan sepanjang dinding pipa terutama pada pipa lengkung (elbow) yang mengakibat kerugian tekanan atau head loss [2].. 
2) Terbentuknya turbulensi akibat gerakan relatif dalam molekul fluida yang dipengaruhi oleh viskositas fluida [3].

3) Semakin besar debit aliran dalam pipa akan mengakibatkan nilai head loss juga semakin besar [4].

Untuk mengatasi masalah-masalah tersebut banyak dilakukan berbagai penelitian terhadap fluida. Seperti pada tahun 1883, Osborne Reynold melakukan eksperimen melalui pipa klasiknya yang memperlihatkan pentingnya bilangan Reynold dalam aliran fluida [3].

Dan tujuan dilakukannya penelitian ini adalah untuk mengetahui pengaruh perubahan laju aliran terhadap tekanan dan jenis aliran pada fluida. Sehingga pada akhirnya nanti alat ini juga dapat digunakan sebagai alat uji praktikum untuk menambah wawasan keilmuan tentang fluida.

\section{TINJAUAN PUSTAKA}

\subsection{Laboratorium}

Mekanika fluida adalah telaah tentang fluida yang bergerak atau diam dan akibat yang ditimbulkan oleh fluida tersebut pada batasnya [5].. Untuk mendukung teori pada mata kuliah mekanika fluida, mahasiswa memerlukan praktek langsung di laboratorium. Laboratorium ialah tempat untuk melatih mahasiswa dalam hal keterampilan melakukan praktek, demonstrasi, percobaan, penelitian, dan pengembangan ilmu pengetahuan. Sarana dan prasarana yang ada di laboratorium dapat mendukung dalam mempraktekkan konsep yang telah dipelajari mahasiswa untuk meningkatkan prestasi belajarnya, terutama dalam bidang mekanika fuida. Keberadaaan laboratorium sebagai tempat praktikum sangat diperlukan untuk peningkatan keterampilan mahasiswa. Pelaksanaan kegiatan praktikum dilakukan dalam pemberian pengalaman belajar kepada mahasiswa, agar mahasiswa dapat berinteraksi dengan bahan-bahan pelajaran dan pengamatan gejala secara langsung yang terjadi pada alat uji fluida tersebut. Kegiatan praktek di laboratorium dapat meningkatkan keterampilan mahasiswa apabila digunakan secara efisien, karena dengan praktek mahasiswa dapat memahami mata kuliah yang memerlukan penghayatan kongkrit tentang fluida dengan melakukan kegiatan nyata melalui praktek.

\subsection{Fluida}

Secara khusus, fluida didefinisikan sebagai zat yang berdeformasi terusmenerus selama dipengaruhi suatu tegangan geser. Fluida atau zat cair dibedakan dari benda padat karena kemampuannya untuk mengalir. Fluida lebih mudah mengalir karena ikatan molekul dalam fluida jauh lebih kecil dari ikatan molekul dalam zat padat, akibatnya fluida mempunyai hambatan yang relatif kecil pada perubahan bentuk karena gesekan [6 \& 7].. Zat padat mempertahankan suatu bentuk dan ukuran yang tetap, sekalipun suatu gaya yang besar diberikan pada zat padat tersebut, zat padat tidak mudah berubah bentuk maupun volumenya, sedangkan zat cair dan gas, zat cair tidak mempertahankan bentuk yang tetap, zat cair mengikuti bentuk wadahnya dan volumenya dapat diubah hanya jika diberikan padanya gaya yang sangat besar dan gas tidak mempunyai bentuk dan maupun volume yang tetap, gas akan berkembang mengisi seluruh wadah. Karena zat cair dan gas tidak mempertahankan suatu bentuk yang tetap, keduanya mempunyai kemampuan untuk mengalir. Dengan demikian kedua-duanya sering secara kolektif disebut sebagai fluida.

Fluida secara umum bila dibedakan dari sudut kemampatannya (compresibility), 
maka bentuk fluida terbagi dua jenis, yaitu; compressible fluid dan incompressible fluid. compressible fluid adalah fluida yang tingkat kerapatannya dapat berubah-ubah, contohnya; zat berbentuk gas. incompressible fluid adalah fluida yang tingkat kerapatannya tidak berubah atau perubahannya kecil sekali dan dianggap tidak ada, contohnya; zat berbentuk cair.

\subsection{Pompa Sentrifugal}

Pompa merupakan pesawat angkut yang bertujuan untuk memindahkan zat cair melalui saluran tertutup. Pompa menghasilkan suatu tekanan yang sifatnya hanya mengalir dari suatu tempat ke tempat yang bertekanan lebih rendah. Atas dasar kenyataan tersebut maka pompa harus mampu membangkitkan tekanan fluida sehingga dapat mengalir atau berpindah [8 \& 9]. Sedangkan pompa sentrifugal adalah suatu mesin yang mengubah energi mekanik dalam bentuk kerja poros menjadi energi fluida. Pompa sentrifugal mempunyai sebuah impeller (baling-baling) untuk mengangkat zat cair dari tempat yang lebih rendah ke tempat yang lebih tinggi. Daya dari luar diberikan kepada poros pompa untuk memutarkan impeller di dalam zat cair. Maka zat cair yang ada di dalam impeller, oleh dorongan sudu-sudu ikut berputar. Karena timbul gaya sentrifugal maka zat cair mengalir dari tengah impeler keluar melalui saluran diantara sudu-sudu. Disini head tekanan zat cair menjadi lebih tinggi. Demikian juga head kecepatannya bertambah besar karena zat cair mengalami percepatan. Zat cair yang keluar dari impeler ditampung oleh saluran berbentuk volut (spiral) dikeliling impeller dan disalurkan ke luar pompa melalui nosel. Di dalam nosel ini sebagian head kecepatan aliran diubah menjadi head tekanan. Jadi impeller pompa berfungsi memberikan kerja kepada zat cair sehingga energi yang dikandungnya menjadi bertambah besar.

\section{METODELOGI PENELITIAN}

\subsection{Alat Uji}

Alat ini dirancang berdasarkan teori yang telah ada, pengalaman dosen pembimbing, serta bahan yang tersedia di pasaran. Desain alat uji dibuat sesederhana mungkin tanpa mengesampingkan ketelitian hasil pengukurannya. Alat uji ini dirancang sebagai alat uji skala laboratorium, yaitu suatu penggunaan alat uji yang hanya ditujukan untuk penelitian serta pengambilan data dari sample fluida yang akan dilakukan penelitian.

\subsection{Cara Kerja Alat Uji}

Pada rancangan alat uji, fluida ditempatkan di bak penampungan air. Kemudian dari bak penampungan ini akan ada dua saluran keluar dimana saluran pipa bagian bawah (pipa utama) akan terhubung dengan pompa dan saluran pipa bagian atas berfungsi sebagai pipa by-pass. Pada saat katup bypass terbuka penuh maka aliran dari pompa akan kembali lagi menuju bak penampungan sehingga tidak akan ada fluida yang menuju ke pipa uji. Sesaat setelah katup by-pass mulai ditutup dan katup utama dibuka maka fluida akan mengalir melalui pipa uji. Prinsip kerja alat ini adalah dengan mengsirkulasikan fluida dari bak penampungan air kembali ke bak penampungan air tersebut melalui pipa yang disambungkan pada sebuah pompa sentrifugal. Sesaat setelah pompa dihidupkan, aliran fluida bergerak dari bak air menuju pipa bagian bawah kemudian memasuki impeller pompa dan menuju instalasi pipa pengujian. Untuk mengetahui besarnya perbedaan tekanan pada pipa-pipa pengujian, dapat dilihat pada manometer U. Sampai akhirnya aliran disirkulasikan kembali ke dalam bak penampungan air. 


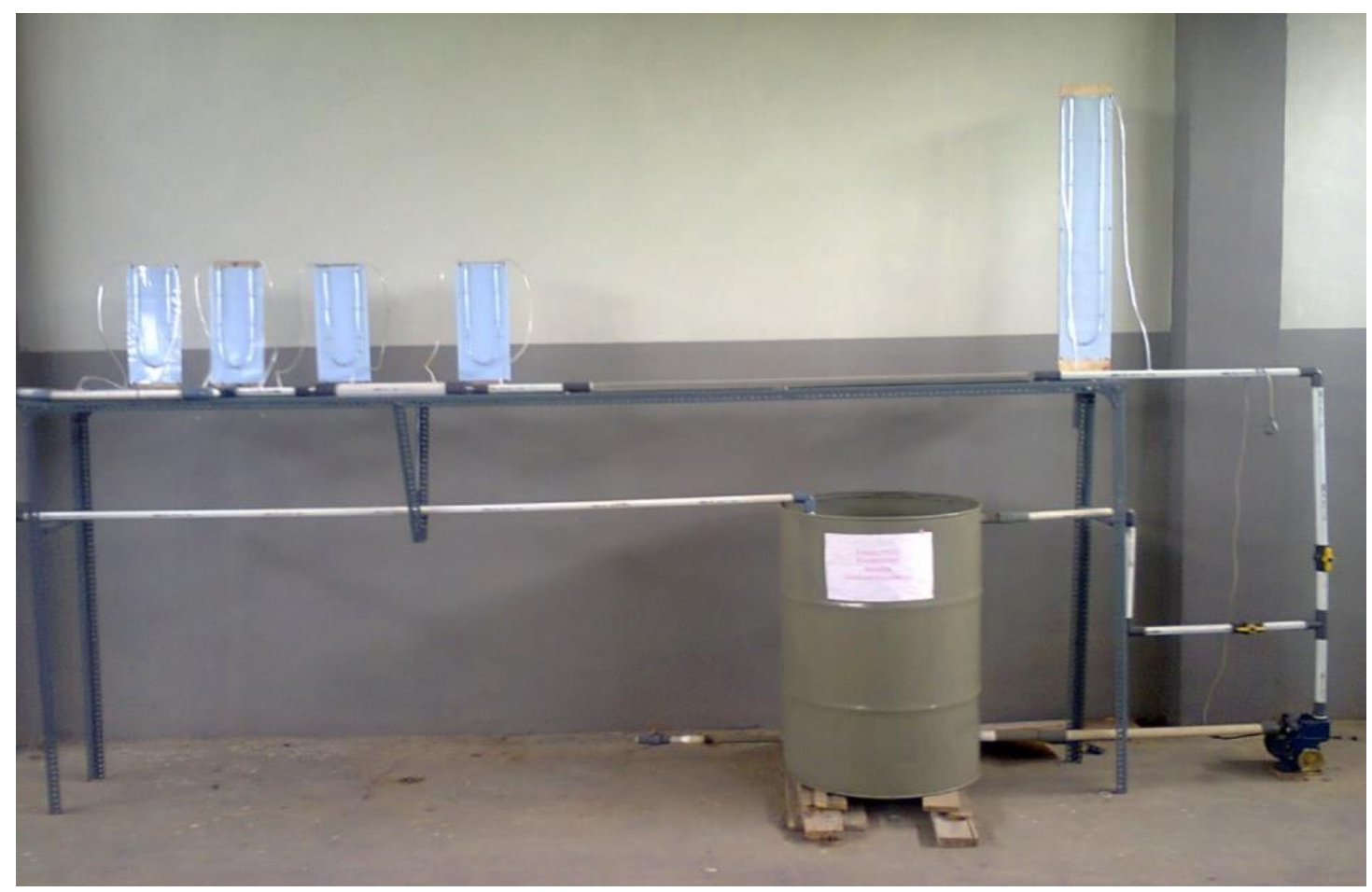

Gambar 1. Alat uji praktikum mekanika fluida

\subsection{Deskripsi Alat Uji}

Komponen - komponen yang digunakan pada alat uji ini adalah :

\section{A. Komponen Utama :}

1) Rangkaian Pipa, digunakan untuk mengsirkulasikan fluida dari bak penampungan air ke seluruh rangkaian pipa uji. Rangkaian pipa menggunakan pipa $P V C$ yang berdiameter $3 / 4$ inchi.

2) Pompa Sentrifugal, berfungsi sebagai alat yang mengalirkan fluida dari bak penampungan air ke rangkaian pipa. Pompa yang digunakan memiliki daya sebesar 125 watt dan putarannya 2970 rpm.

3) Pipa Pengujian, digunakan untuk melakukan pengujian tekanan dan jenis aliran. Pipa yang digunakan untuk pengujian adalah pipa $P V C$, acrylic dan besi yang berdiameter $3 / 4$ inchi.

4) Bak Penampungan Air, merupakan tempat beradanya fluida yang digunakan untuk penelitian. Bak penampungan terbuat dari drum besi.

5) Katup, berfungsi untuk mengatur kecepatan aliran fluida pada pipa pengujian.
6) Manometer U, berfungsi untuk mengukur perbedaan tekanan yang terjadi antara dua titik pada pipa penguji.

7) Meja Penyangga, sebagai penopang instalasi alat uji. Dirangkai menggunakan besi siku.

B. Komponen Pendukung :

1) Gelas Ukur,

2) Stopwatch,

3) Ember,

4) Gergaji Besi,

5) Mesin Bor,

6) Lem Paralon,

7) Lem Silikon,

\subsection{Tahap Pengujian}

Tahap-tahap pengujian yang dilakukan pada saat pengambilan data adalah sebagai berikut :

1) Masukkan fluida (air) ke dalam bak penampungan.

2) Hidupkan pompa, pastikan semua katup dalam keadaan terbuka hal ini bertujuan untuk menstabilkan aliran pada saat pengambilan data. 
3) Tutup perlahan katup by-pass sehingga didapat laju aliran yang bervariasi pada pipa uji.

4) Tahap pengambilan data :

a. Mengatur bukaan katup pada posisi tertentu,

b. Aliran dibiarkan bersirkulasi beberapa saat sampai stabil. i. Mengulangi pengambilan data dengan mengatur bukaan katup dari minimal sampai maksimal agar terjadi perubahan laju aliran.

j. Melihat dan mencatat perubahan tekanan yang terjadi pada pipapipa uji karena pengaruh perubahan laju aliran.

k. Pengujian dilakukan berulang-

Tabel 1. Perbedaan tinggi tekanan pada masing-masing pipa

\begin{tabular}{|c|c|c|c|c|c|c|c|}
\hline No & $\mathrm{Q}$ & $\mathrm{h}_{1}$ & $\mathrm{~h}_{2}$ & $\mathrm{~h}_{3}$ & $\mathrm{~h}_{4}$ & $\mathrm{~h}_{5}$ & $\mathrm{~h}_{6}$ \\
\hline 1 & 0,00015 & 0,012 & 0,021 & 0,004 & 0,002 & 0,002 & 0,004 \\
\hline 2 & 0,00018 & 0,037 & 0,018 & 0,01 & 0,004 & 0,003 & 0,008 \\
\hline 3 & 0,00021 & 0,054 & 0,016 & 0,015 & 0,005 & 0,006 & 0,011 \\
\hline 4 & 0,00024 & 0,078 & 0,015 & 0,025 & 0,007 & 0,008 & 0,014 \\
\hline 5 & 0,00027 & 0,092 & 0,013 & 0,029 & 0,009 & 0,012 & 0,018 \\
\hline 6 & 0,0003 & 0,124 & 0,012 & 0,035 & 0,012 & 0,014 & 0,024 \\
\hline 7 & 0,00033 & 0,148 & 0,008 & 0,04 & 0,015 & 0,016 & 0,028 \\
\hline 8 & 0,00036 & 0,168 & $-0,012$ & 0,049 & 0,021 & 0,017 & 0,036 \\
\hline 9 & 0,00039 & 0,225 & $-0,033$ & 0,055 & 0,027 & 0,019 & 0,044 \\
\hline 10 & 0,00041 & 0,252 & $-0,052$ & 0,068 & 0,034 & 0,021 & 0,049 \\
\hline
\end{tabular}

c. Mencatat debit fluida yang mengalir,

d. Melihat dan mencatat perbedaan tekanan di manometer $U$ yang terjadi pada satu titik bagian pipa,

e. Melihat dan mencatat perbedaan tekanan di manometer $U$ yang terjadi pada pipa yang mengalami pembesaran,

f. Melihat dan mencatat perbedaan tekanan di manometer $\mathrm{U}$ yang terjadi pada pipa yang mengalami pengecilan,

g. Melihat dan mencatat perbedaan tekanan di manometer $U$ yang terjadi pada pipa yang mengalami belokan,

h. Melihat dan mencatat perubahan tekanan di manometer $U$ yang terjadi pada pipa yang memiliki perbedaan bahan, ulang untuk mendapatkan data yang baik dan benar, kerja alat penguji selalu deperiksa agar sirkulasi aliran tetap stabil sehingga penyimpangan data sekecil mungkin.

1. Setelah semuanya selesai, rapikan semua peralatan yang digunakan dan tutup semua katup agar tidak terjadi pengendapan di rangkaian pipa. Apabila akan kembali melakukan pengujian, endapan ini dapat mengganggu sirkulasi air.

m. Mengolah data-data yang sudah didapatkan, dengan melakukan perhitungan dan melengkapinya dengan membuat tabel dan grafik. 


\section{HASIL DAN PEMBAHASAN}

\subsection{Data Penelitian}

Dari penelitian yang dilakukan berulang kali, mulai dari debit 0,00015 $\mathrm{m}^{3} /$ detik sampai debit $0,00041 \mathrm{~m}^{3} /$ detik didapat data seperti pada tabel 1 di atas:

$\mathrm{Q}=$ Debit aliran fluida $\left(\mathrm{m}^{3} / \mathrm{det}\right)$

$\mathrm{h}_{1}=$ Perbedaan tinggi pada pipa tekanan udara luar (m)

$\mathrm{h}_{2}=$ Perbedaan tinggi pada pipa pembesaran $(\mathrm{m})$

$\mathrm{h}_{3}=$ Perbedaan tinggi pada pipa pengecilan $(\mathrm{m})$

$\mathrm{h}_{4}=$ Perbedaan tinggi pada pipa belokan (m)

$\mathrm{h}_{5}=$ Perbedaan tinggi pada pipa lain bahan (m)

$\mathrm{h}_{6}=$ Perbedaan tinggi pada pipa lurus (m)

\subsection{Perhitungan}

1) Berat Jenis Fluida :

$\gamma=\rho \cdot g \quad\left(\mathrm{~N} / \mathrm{m}^{3}\right)$

$\gamma=1000 \mathrm{~kg} / \mathrm{m}^{3} \cdot 9,81 \mathrm{~m} / \mathrm{s}^{2}$

$\gamma=9810 \mathrm{~N} / \mathrm{m}^{3}$

2) Kecepatan aliran fluida :

Kecepatan aliran fluida dalam pipa $p v c$ dengan diameter $3 / 4$ inchi pada debit $0,00015 \mathrm{~m}^{3} /$ detik :

$\mathrm{V}=\frac{\mathrm{Q}}{\frac{\pi}{4} \mathrm{D}^{2}} \quad(\mathrm{~m} / \mathrm{det})$

$\mathrm{V}=\frac{0,00015 \mathrm{~m}^{3} / \mathrm{det}}{\frac{3,14}{4}(0,019 \mathrm{~m})^{2}}$

$\mathrm{V}=\frac{0,00015 \mathrm{~m}^{3} / \mathrm{det}}{0,00028 \mathrm{~m}^{2}}$

$\mathrm{V}=0,535 \mathrm{~m} / \mathrm{det}$

3) $\operatorname{Re}=\frac{\mathrm{V} \cdot \mathrm{D}}{v}$

$v=$ viskositas kinetik fluida $=0.801 .10^{-6}$ $\mathrm{m}^{2} / \mathrm{det}$

Bilangan Reynolds dalam pipa acrylic pada debit $0,00015 \mathrm{~m}^{3} /$ det :

$$
\begin{aligned}
\operatorname{Re} & =\frac{0,535 \mathrm{~m} / \text { det } \cdot 0,019 \mathrm{~m}}{0.801 \cdot 10^{-6} \mathrm{~m}^{2} / \text { det }} \\
\operatorname{Re} & =\frac{0,0101 \mathrm{~m}^{2} / \text { det }}{0.801 \cdot 10^{-6} \mathrm{~m}^{2} / \text { det }} \\
\operatorname{Re} & =0,01269039 \cdot 10^{6} \\
\operatorname{Re} & =12690,39
\end{aligned}
$$

4) Perhitungan besar tekanan pada satu titik dalam pipa lurus $\left(\mathrm{P}_{1}\right)$.

$$
\begin{aligned}
& \mathrm{P}_{1}=\mathrm{P}_{\text {udara }}+\rho \cdot \mathrm{g} \cdot \mathrm{h}_{1} \quad\left(\mathrm{~N} / \mathrm{m}^{2}\right) \\
& \mathrm{P}_{\text {udara }}=1 \mathrm{~atm}=101325 \mathrm{~N} / \mathrm{m}^{2}
\end{aligned}
$$

Perhitungan besar tekanan pada satu titik dalam pipa lurus $\left(\mathrm{P}_{1}\right)$ pada debit 0,00015 : $\mathrm{P}_{1}=101325 \mathrm{~N} / \mathrm{m}^{2}+1000 \mathrm{~kg} / \mathrm{m}^{3} \cdot 9,81 \mathrm{~m} / \mathrm{s}^{2}$. $0,012 \mathrm{~m}$

$\mathrm{P}_{1}=101325 \mathrm{~N} / \mathrm{m}^{2}+117,72 \mathrm{~N} / \mathrm{m}^{2}$

$\mathrm{P}_{1}=101442,72 \mathrm{~N} / \mathrm{m}^{2}$

5) Perhitungan perubahan tekanan pipa pembesaran $\left(\Delta \mathrm{P}_{2}\right)$ pada debit 0,00015 :

$\Delta \mathrm{P}_{2}=\rho \cdot \mathrm{g} \cdot \mathrm{h}_{2}$ $\Delta \mathrm{P}_{2}=1000 \mathrm{~kg} / \mathrm{m}^{3} \cdot 9,81 \mathrm{~m} / \operatorname{det}^{2} \cdot 0,021 \mathrm{~m}$ $\Delta \mathrm{P}_{2}=206,01 \mathrm{~N} / \mathrm{m}^{2}$

6) Perhitungan besar tekanan pipa pengecilan $\left(\Delta \mathrm{P}_{3}\right)$ pada debit 0,00015 :

$\Delta \mathrm{P}_{3}=\rho \cdot \mathrm{g} \cdot \mathrm{h}_{3}$ $\Delta \mathrm{P}_{3}=1000 \mathrm{~kg} / \mathrm{m}^{3} \cdot 9,81 \mathrm{~m} / \mathrm{s}^{2} \cdot 0,004 \mathrm{~m}$ $\Delta \mathrm{P}_{3}=39,24 \mathrm{~N} / \mathrm{m}^{2}$

7) Perhitungan besar tekanan pipa belokan $\left(\Delta \mathrm{P}_{4}\right)$ pada debit 0,00015 :

$\Delta \mathrm{P}_{4}=\rho \cdot \mathrm{g} \cdot \mathrm{h}_{4}$ $\Delta \mathrm{P}_{4}=1000 \mathrm{~kg} / \mathrm{m}^{3} \cdot 9,81 \mathrm{~m} / \mathrm{s}^{2} \cdot 0,002 \mathrm{~m}$ $\Delta \mathrm{P}_{4}=19,62 \mathrm{~N} / \mathrm{m}^{2}$

8) Perhitungan perubahan tekanan pipa beda bahan $\left(\Delta \mathrm{P}_{5}\right)$ pada debit 0,00015:

$\Delta \mathrm{P}_{5}=\rho \cdot g \cdot \mathrm{h}_{5}$ $\Delta \mathrm{P}_{5}=1000 \mathrm{~kg} / \mathrm{m}^{2} \cdot 9,81 \mathrm{~m} / \mathrm{s}^{2} \cdot 0,002 \mathrm{~m}$ $\Delta \mathrm{P}_{5}=19,62 \mathrm{~N} / \mathrm{m}^{2}$

9) Perhitungan perubahan tekanan pipa lurus $\left(\Delta \mathrm{P}_{6}\right)$ pada debit 0,00015 : 
$\Delta \mathrm{P}_{6}=\rho \cdot \mathrm{g} \cdot \mathrm{h}_{6}$

$\Delta \mathrm{P}_{6}=1000 \mathrm{~kg} / \mathrm{m}^{3} \cdot 9,81 \mathrm{~m} / \mathrm{s}^{2} \cdot 0,004 \mathrm{~m}$ $\Delta \mathrm{P}_{6}=39,24 \mathrm{~N} / \mathrm{m}^{2}$

\subsection{PEMBAHASAN}

Setelah dilakukan perhitungan, maka didapat data perubahan tekanan yang terjadi pada setiap pipa yang disebabkan karena perubahan laju aliran sebagai berikut :

Q = Debit aliran fluida $\left(\mathrm{m}^{3} / \mathrm{det}\right)$
$\mathrm{P}_{1} \quad=$ Besarnya tekanan pada satu titik bagian pipa $\left(\mathrm{N} / \mathrm{m}^{2}\right)$

$\Delta \mathrm{P}_{2}=$ Besarnya perubahan tekanan pada pipa pembesaran $\left(\mathrm{N} / \mathrm{m}^{2}\right)$

$\Delta \mathrm{P}_{3}=$ Besarnya perubahan tekanan pada pipa pengecilan $\left(\mathrm{N} / \mathrm{m}^{2}\right)$

$\Delta \mathrm{P}_{4}=$ Besarnya perubahan tekanan pada pipa belokan $\left(\mathrm{N} / \mathrm{m}^{2}\right)$

$\Delta \mathrm{P}_{5}=$ Besarnya perubahan tekanan pada pipa beda bahan $\left(\mathrm{N} / \mathrm{m}^{2}\right)$

$\Delta \mathrm{P}_{6}=$ Besarnya perubahan tekanan pada pipa lurus $\left(\mathrm{N} / \mathrm{m}^{2}\right)$

Tabel 2. Besar Perubahan Tekanan Pada Masing-Masing Pipa

\begin{tabular}{|c|c|c|c|c|c|c|c|}
\hline No & $\mathrm{Q}$ & $\mathrm{P}_{1}$ & $\Delta \mathrm{P}_{2}$ & $\Delta \mathrm{P}_{3}$ & $\Delta \mathrm{P}_{4}$ & $\Delta \mathrm{P}_{5}$ & $\Delta \mathrm{P}_{6}$ \\
\hline 1 & 0,00015 & 101443 & 206,01 & 39,24 & 19,62 & 19,62 & 39,24 \\
\hline 2 & 0,00018 & 101688 & 176,58 & 98,1 & 39,24 & 29,43 & 78,48 \\
\hline 3 & 0,00021 & 101855 & 156,96 & 147,15 & 49,05 & 58,86 & 107,91 \\
\hline 4 & 0,00024 & 102090 & 147,15 & 245,25 & 68,67 & 78,48 & 137,34 \\
\hline 5 & 0,00027 & 102228 & 127,53 & 284,49 & 88,29 & 117,72 & 176,58 \\
\hline 6 & 0,0003 & 102541 & 117,72 & 343,35 & 117,72 & 137,34 & 235,44 \\
\hline 7 & 0,00033 & 102777 & 78,48 & 392,4 & 147,15 & 156,96 & 274,68 \\
\hline 8 & 0,00036 & 102973 & $-117,72$ & 480,69 & 206,01 & 166,77 & 353,16 \\
\hline 9 & 0,00039 & 103532 & $-323,73$ & 539,55 & 264,87 & 186,39 & 431,64 \\
\hline 10 & 0,00041 & 103797 & $-510,12$ & 667,08 & 333,54 & 206,01 & 480,69 \\
\hline
\end{tabular}




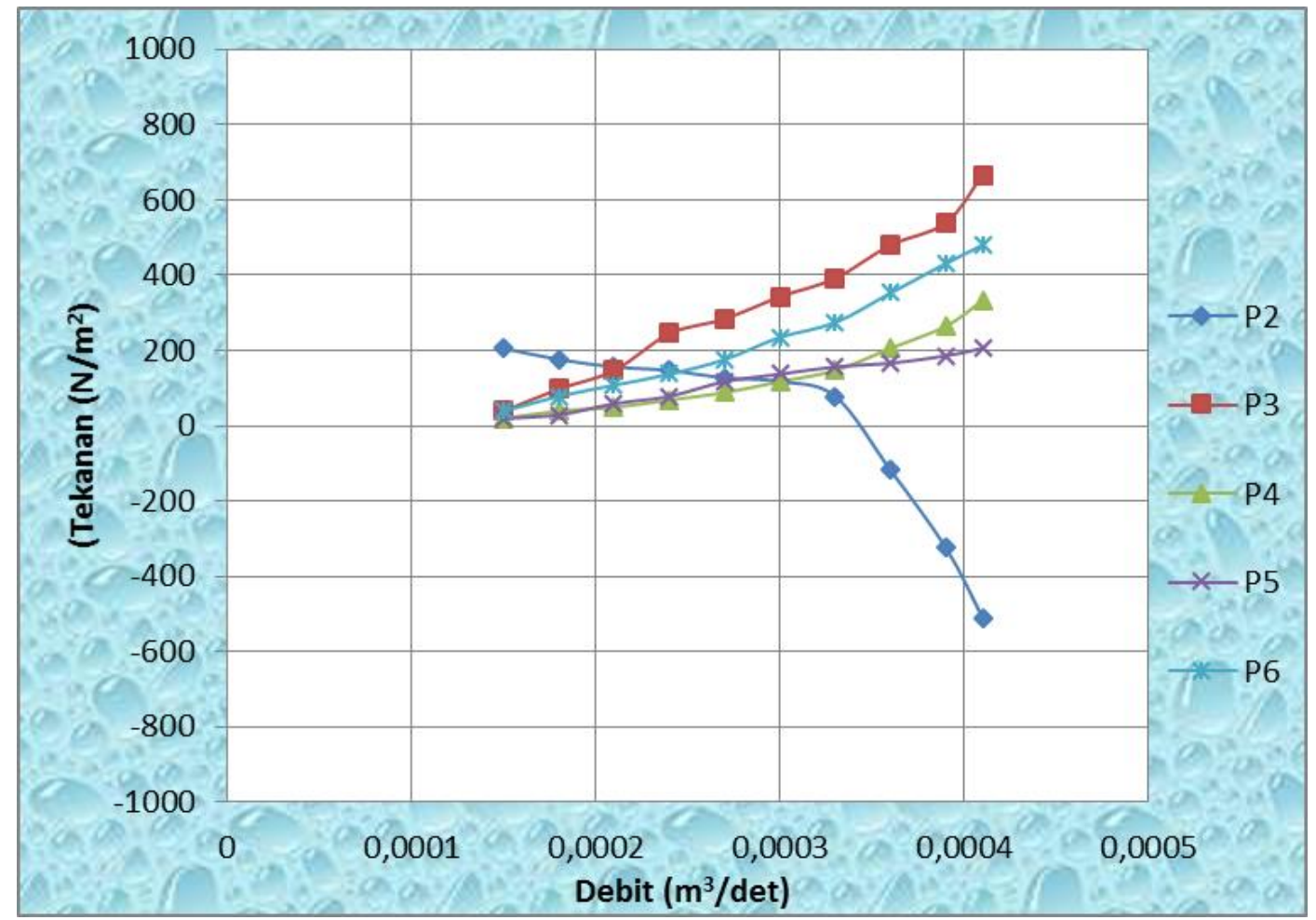

Gambar 2. Grafik perubahan tekanan pada masing-masing pipa

Pada diameter pipa yang sama dan debit yang semakin besar, laju aliran fluida sangat mempengaruhi perubahan tekanan dan jenis aliran fluida. Hal ini diketahui dari pengujian, pada pipa berdiameter $3 / 4$ inchi $\left(\mathrm{P}_{1}, \Delta \mathrm{P}_{3}, \Delta \mathrm{P}_{4}, \Delta \mathrm{P}_{5}\right.$, dan $\left.\Delta \mathrm{P}_{6}\right)$ pada debit $0,00015 \mathrm{~m}^{3} /$ detik nilai besar tekanan semakin besar dengan semakin bertambahnya debit aliran. Misalnya ada $\mathrm{P}_{1}$, dengan debit sebesar $0,00015 \mathrm{~m}^{3} /$ detik tekanan yang terjadi sebesar $101443 \mathrm{~N} / \mathrm{m}^{2}$ dan terus meningkat sampai pada debit 0,00041 $\mathrm{m}^{3} /$ detik debitnya sebesar $103797 \mathrm{~N} / \mathrm{m}^{2}$. Hal yang sebalikya terjadi pada pipa pembesaran $\left(\Delta \mathrm{P}_{2}\right)$ dengan diameter pipa 1,5 inchi semakin besar laju aliran, maka tekanannya menjadi negatif. Hal ini karena di dalam pipa yang berdiameter 1,5 inchi laju alirannya semakin rendah namun tekanannya semakin tinggi.

Sementara untuk jenis aliran di dalam pipa, dilihat dari bilangan Reynold yang sebesar 12690,39 sampai 343631,71, bilangan Reynold lebih besar dari 4000 . Dan bilangan Reynold yang lebih besar dari 4000 adalah aliran turbulen. Aliran turbulen adalah jenis aliran dimana pergerakan dari partikel - partikel fluida sangat tidak menentu karena mengalami percampuran serta putaran partikel antar lapisan, yang mengakibatkan saling tukar momentum satu bagian fluida kebagian fluida yang lain dalam skala yang besar. Bilangan Reynold sendiri dipengaruhi oleh kecepatan aliran fluida $\left(\mathrm{V}_{\mathrm{f}}\right)$, diameter dalam pipa pengujian (D) dan viskositas kinematik fluida (v). Semakin bertambahnya kecepatan fluida, maka bilangan Reynold juga akan bertambah. Ini dapat dibuktikan bahwa pada bilangan Reynold 12690,39 kecepatan aliran fluidanya adalah $0,535 \mathrm{~m} / \mathrm{det}$, dan pada bilangan Reynold 343631,71 kecepatan fluidanya adalah $1,46 \mathrm{~m} /$ det.

Perubahan tekanan di dalam pipa pengujian terjadi seiring bertambahnya laju aliran fluida. Untuk besar tekanan pada pipa pengujian pada satu titik bagian pipa $\left(\mathrm{P}_{1}\right)$, besar tekanannya akan semakin bertambah dengan semakin bertambahnya laju aliran. Hal ini dapat diketahui, pada debit $0,00015 \mathrm{~m}^{3} /$ detik besar tekanannya adalah $101443 \mathrm{~N} / \mathrm{m}^{2}$ dan semakin bertambah pada debit $0,00041 \mathrm{~m}^{3} /$ detik tekanannya menjadi 
$103797 \mathrm{~N} / \mathrm{m}^{2}$. Untuk besar tekanan pada pipa pembesaran $\left(\Delta \mathrm{P}_{2}\right)$ terjadi sebaliknya, semakin bertambahnya laju aliran tekanan yang terjadi semakin kecil. Pada debit 0,00015 tekanannya sebesar 206,01 $\mathrm{N} / \mathrm{m}^{2}$, sedangkan pada debit 0,00041 $\mathrm{m}^{3} /$ detik tekanannya adalah $-510,12$ $\mathrm{N} / \mathrm{m}^{2}$. Sementara perubahan tekanan pada pipa pengecilan $\left(\Delta \mathrm{P}_{3}\right)$ berbanding terbalik dengan yang terjadi pada pipa pembesaran $\left(\Delta \mathrm{P}_{2}\right)$, pada debit 0,00015 $\mathrm{m}^{3} /$ detik, tekanannya adalah $39,24 \mathrm{~N} / \mathrm{m}^{2}$ dan terus meningkat pada debit 0,00041 $\mathrm{m}^{3} /$ detik tekanannya menjadi sebesar $667,08 \mathrm{~N} / \mathrm{m}^{2}$. Pada pipa belokan $\left(\Delta \mathrm{P}_{4}\right)$, tekanannya juga berbanding lurus dengan semakin bertambahnya laju aliran fluida. Pada debit $0,00015 \mathrm{~m}^{3} /$ detik tekanannya adalah $19,62 \mathrm{~N} / \mathrm{m}^{2}$ dan terus bertambah pada debit 0,00041 tekanannya menjadi $333,54 \mathrm{~N} / \mathrm{m}^{2}$. Semakin bertambahnya laju aliran maka semakin besar juga perubahan tekanan juga terjadi pada pipa beda bahan $\left(\Delta \mathrm{P}_{5}\right)$, pada debit 0,00015 $\mathrm{m}^{3} /$ detik tekananya adalah $19,62 \mathrm{~N} / \mathrm{m}^{2}$ dan pada debit $0,00041 \mathrm{~m}^{3} /$ detik adalah 206,01. Begitu juga pada pipa lurus $\left(\Delta \mathrm{P}_{6}\right)$, pada debit 0,00015 perubahan tekananya sebesar $39,24 \quad \mathrm{~N} / \mathrm{m}^{2}$ dan semakin bertambah pada debit 0,00041 $\mathrm{m}^{3} /$ detik, tekananya sebesar $480,69 \mathrm{~N} / \mathrm{m}^{2}$.

\section{KESIMPULAN DAN SARAN}

\subsection{Kesimpulan}

Berdasarkan hasil penelitian dan perhitungan dapat disimpulkan bahwa :

1) Perubahan tekanan yang terjadi pada satu titik bagian pipa $\left(\mathrm{P}_{1}\right)$, pipa pengecilan $\left(\Delta \mathrm{P}_{3}\right)$, pipa belokan $\left(\Delta \mathrm{P}_{4}\right)$, pipa beda bahan $\left(\Delta \mathrm{P}_{5}\right)$ dan pipa lurus $\left(\Delta \mathrm{P}_{6}\right)$ berbanding lurus dengan semakin bertambahnya laju aliran fluida. Sementara tekanan pada pipa pembesaran $\left(\Delta \mathrm{P}_{2}\right)$ berbanding terbalik dengan semakin bertambahnya laju aliran fluida.

2) Jenis aliran yang terjadi pada alat uji adalah jenis aliran turbulen. Karena bilangan Reynoldnya di atas 4000, yaitu 12690,93 .

3) Berdasarkan penelitian perubahan tekanan masing-masing pipa pengujian pada debit $0,00015 \mathrm{~m}^{3} /$ detik sampai $0,00041 \mathrm{~m}^{3} /$ detik adalah :

a. Pada satu titik bagian pipa $\left(\mathrm{P}_{1}\right)$ tekanannya $101443 \mathrm{~N} / \mathrm{m}^{2}$, menjadi 103797 N/m².

b. Pada pipa pembesaran $\left(\Delta \mathrm{P}_{2}\right)$ perubahan tekanannya $206,01 \mathrm{~N} / \mathrm{m}^{2}$, menjadi $-510,12 \mathrm{~N} / \mathrm{m}^{2}$.

c. Pada pipa pengecilan $\left(\Delta \mathrm{P}_{3}\right)$ perubahan tekanannya $39,24 \mathrm{~N} / \mathrm{m}^{2}$ menjadi $667,08 \mathrm{~N} / \mathrm{m}^{2}$.

d. Pada pipa belokan $\left(\Delta \mathrm{P}_{4}\right)$ perubahan tekanannya $19,62 \quad \mathrm{~N} / \mathrm{m}^{2}$ menjadi $333,54 \mathrm{~N} / \mathrm{m}^{2}$.

e. Pada pipa beda bahan $\left(\Delta \mathrm{P}_{5}\right)$ perubahan tekanannya $19,62 \mathrm{~N} / \mathrm{m}^{2}$ $206,01 \mathrm{~N} / \mathrm{m}^{2}$.

f. Pada pipa lurus $\left(\Delta \mathrm{P}_{6}\right)$ perubahan tekananya sebesar $39,24 \quad \mathrm{~N} / \mathrm{m}^{2}$ menjadi $480,69 \mathrm{~N} / \mathrm{m}^{2}$.

\subsection{Saran}

Agar penelitian dapat berjalan lebih baik, hal-hal yang perlu diperhatikan adalah :

1) Tidak terjadi kebocoran pada instalasi pipa, terutama pada berbagai pipa yang akan diambil datanya.

2) Tidak terjadi kebocoran pada selang manometer U.

3) Untuk mendapatkan pengukuran debit yang lebih akurat dan lebih cepat, pada pengujian selanjutnya sebaiknya menggunakan flow meter.

\section{DAFTAR PUSTAKA}

[1] Negara, Priana Wendy, 2011, Perbandingan Analisa Pressure Drop pada Pipa Lengkung $90^{\circ}$ Standar ANSI B36.10 dengan COSMOSflow Works 2007, Jurnal Teknik Mesin, Universitas Gunadarma, Jakarta. 
[2] Kaprawi, 2009, Aliran Dalam Pipa Lengkung $90^{\circ}$ dengan Radius Bervariasi, Jurnal Rekayasa Mesin, Vol. 9, No. 3.

[3] Munson Bruce R., Young Donald F., Okiishi Theodore H. (2003). Mekanika Fluida Edisi Empat Jilid 1 dan 2. Jakarta : Penerbit Erlangga.

[4] Helmizar, 2011, Studi Eksperimental Tentang Head loss pada Aliran Fluida yang melalui Elbow $90^{\circ}$, Jurnal Ilmiah Teknik Mesin Cakra M, Vol. 5 no. 1, Hal. 26-31.

[5] Tipler, P.A. (1998). Fisika untuk Sains dan Teknik-Jilid I. Jakarta : Penebit Erlangga

[6] White Frank M. (1994). Mekanika Fluida Edisi Kedua Jilid 1. Jakarta: Penerbit Erlangga

[7] Stereeter. V. L. Mekanika Fluida Jilid 1. (1993). Jakarta: Penerbit Erlangga.

[8] Church Austin H. (1993). Pompa dan Blower Sentrifugal. Terjemahan Zulkifli Harahap. Jakarta: Penerbit Erlangga.

[9] Sularso, Tahara Haruo (1983) . Pompa dan Kompresor. Jakarta: Penerbit PT Pradnya Paramita. 